\title{
FloWatch versus conventional pulmonary artery banding
}

\author{
Antonio F. Corno, MD, FRCS, FACC, FETCS, Edmund J. Ladusans, MD, FRCP, Marco Pozzi, MD, FRCS, FETCS, and
} Stephen Kerr, MBBS, FRACP

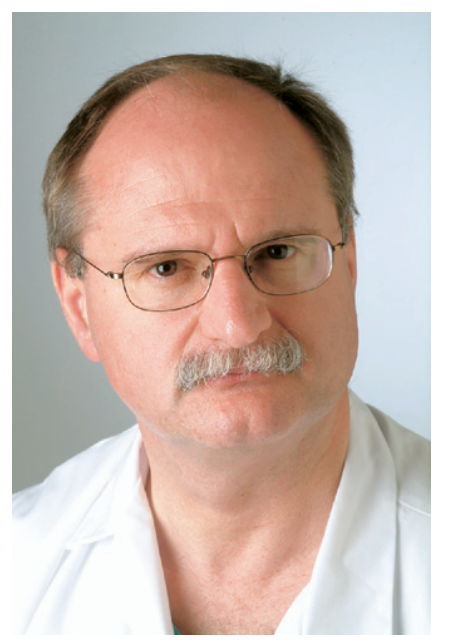

Dr Corno
From Alder Hey Children Hospital, Liverpool, England.

Antonio Corno reports a consulting fee from EndoArt.

Read at the Eighty-seventh Annual Meeting of The American Association for Thoracic Surgery, Washington, DC, May 5-9, 2007.

Received for publication Feb 9, 2007; revisions received March 15, 2007; accepted for publication March 22, 2007.

Address for reprints: Antonio F. Corno, MD, FRCS, FACC, FETCS, Cardiac Surgery, Alder Hey Children Hospital, Eaton Road, Liverpool, L12 2AP, United Kingdom (E-mail: Antonio.Corno@rlc.nhs.uk).

J Thorac Cardiovasc Surg 2007;134:1413-20 0022-5223/\$32.00

Copyright (C) 2007 by The American Association for Thoracic Surgery

doi:10.1016/j.jtcvs.2007.03.065
Objective: We sought to compare the efficacy of conventional pulmonary artery banding with that of FloWatch pulmonary artery banding.

Methods: Forty consecutive infants underwent conventional pulmonary artery banding $(\mathrm{n}=20$; mean age, $1.8 \pm 1.5$ months; mean weight, $3.7 \pm 0.7 \mathrm{~kg})$ or FloWatch pulmonary artery banding $(\mathrm{n}=20$; mean age, $2.6 \pm 1.3$ months; mean weight, $4.1 \pm 0.8 \mathrm{~kg}$ ). Indications were preparation for biventricular repair in 16 of 20 infants, univentricular repair in 2 of 20 infants, and left ventricular retraining in 2 of 20 infants in the conventional pulmonary artery banding group versus 13 of 20,5 of 20 , and 2 of 20 infants, respectively, in the FloWatch pulmonary artery banding group. Twelve of 20 infants required preoperative mechanical ventilation in the conventional pulmonary artery banding group (mean duration, $3.3 \pm 4.3$ days) versus preoperative mechanical ventilation required by 14 of 20 in the FloWatch pulmonary artery banding group (mean duration, $17.5 \pm 19.0$ days; $P<.005$ ).

Results: There were 3 early and 2 late deaths after conventional pulmonary artery banding (mean follow-up, $10.8 \pm 9.6$ months; range, 1-33 months) versus no early and 2 late deaths after FloWatch pulmonary artery banding (mean follow-up, $13.4 \pm$ 10.4 months; range, 1-38 months). Postoperative mechanical ventilation and intensive care unit and hospital stays were significantly longer after conventional pulmonary artery banding than those after FloWatch pulmonary artery banding, respectively $(10.4 \pm 11.2$ vs $3.0 \pm 3.1$ days $[P<.01], 20.3 \pm 19.9$ vs $5.3 \pm 4.6$ days $[P<.005]$, and $45.6 \pm 41.6$ vs $15.4 \pm 6.4$ days $[P<.005])$. Reoperation to adjust the band was required in 7 (35\%) of 20 infants after conventional pulmonary artery banding, whereas no reoperations were required after FloWatch pulmonary artery banding $(P<.005)$. Average cost of stay in the intensive care unit and hospital was, respectively, $\$ 45,000$ and $\$ 45,300$ cheaper with FloWatch pulmonary artery banding than average cost with conventional pulmonary artery banding, largely surpassing the cost of the device $(\$ 10,000)$.

Conclusions: FloWatch pulmonary artery banding appears superior to conventional pulmonary artery banding because (1) reoperations are not required; (2) postoperative management is simplified and postoperative mechanical ventilation, stay in the intensive care unit, and stay in the hospital are significantly reduced; and (3) the reduction in costs of postoperative mechanical ventilation, stay in the intensive care unit, and stay in the hospital significantly outweigh the cost of the device.

I mprovements in the perioperative management of patients with congenital heart defects have made the surgical repair of most of the intracardiac defects a clinical possibility, with good outcomes even in small infants. ${ }^{1}$ Palliation with pulmonary artery banding (PAB) is nowadays rarely considered for simple congenital heart defects, such as isolated ventricular septal defects. Recent clinical reports have considered the PAB for malformations, such as multiple ventricular septal defects, ${ }^{2}$ ventricular septal defects associated with aortic arch interruption, ${ }^{2,3}$ complete atrioventricular septal defects, ${ }^{2,4-7}$ functionally univentricular hearts, ${ }^{2,5,6,8-10}$ 


\author{
Abbreviations and Acronyms \\ conv-PAB = conventional pulmonary artery banding \\ FW-PAB = FloWatch pulmonary artery banding \\ ICU = intensive care unit \\ $\mathrm{PAB}=$ pulmonary artery banding
}

left ventricular retraining in transposition of the great arteries with late referral, ${ }^{11}$ and congenitally corrected transposition of the great arteries. ${ }^{12-14}$ Other indications for PAB include hypoplastic left heart malformations, either as a rescue procedure in critically ill neonates or as an elective preparation for the subsequent operation (ie, either the Norwood procedure to a univentricular repair or heart transplantation). ${ }^{15-18}$

After long-term experimental evaluation in animals, ${ }^{19}$ a telemetrically controlled adjustable PAB device, the FloWatch PAB device (EndoArt, Lausanne, Switzerland), has been successfully introduced in clinical practice in different institutions after positive results were obtained in a multicenter clinical trial. ${ }^{20-22}$ This new implantable, wireless, battery-free device demonstrated the feasibility of repeated progressive occlusions and reopenings of the device to the desired percentage of occlusion through a remote control unit.

The FloWatch PAB device comprises an implantable device (Figure 1) and an external control unit. With the device in the clipped position, the dimensions are as follows: $26 \mathrm{~mm}$ (length) $\times 18 \mathrm{~mm}$ (width) $\times 18 \mathrm{~mm}$ (height). The change in the adjustable area is obtained by means of a piston driven by an incorporated electrical micromotor. The adjustment is done through the external control unit, delivering the energy to the implanted device through an antenna, as well as the commands to drive the microengine. The telemetric system is designed such that the implant sends back to the control unit information about its functioning. Thus the FloWatch PAB device allows easy and repetitive adjustable $\mathrm{PAB}$, avoiding the need for reoperation or any invasive procedure to adjust the band in both ways. ${ }^{19-22}$

The clinical introduction of the FloWatch device (commercially available in Europe, having obtained the EC mark few years ago) as adjustable PAB has substantially modified the management of patients with increased pulmonary artery blood flow and pressure. For indications like Swisscheese multiple ventricular septal defects or complete atrioventricular septal defects with unbalanced ventricles, the FloWatch PAB allows a fast-track operation, a very reliable management of the pulmonary artery blood flow and pressures in the postoperative period, and the possibility of delaying the intracardiac repair for much longer than conventional banding at the desired age and body weight because of the ability of reducing the tightness of the band with the growth of the patient.
In infants with functionally univentricular hearts, the device makes possible repetitive titration of pulmonary artery pressures distal to the narrowing to reach the desired low values and later perform a staged cavopulmonary connection. In patients in whom left ventricular retraining is required because of late referral in the presence of transposition of the great arteries and in congenitally corrected transposition of the great arteries (ie, double discordance), FloWatch PAB is the only technique that allows modifications of the distal pulmonary artery pressure in a fashion suitable with the continuously variable clinical needs of these conditions, generally requiring repeated adjustments and prolonged stay in the intensive care unit (ICU). ${ }^{11,13,23}$

On the contrary, FloWatch PAB has never been used for bilateral banding in hypoplastic left heart syndrome because its size precludes the use of 2 devices, one on each branch of the pulmonary artery.

The clinical experience with this device confirmed in all the above situations a substantial reduction of mortality and morbidity associated with conventional surgical banding in addition to a significant reduction in ICU and hospital stay. ${ }^{20-22}$

Finally, another important advantage of FloWatch PAB is that at the moment of subsequent intracardiac repair and debanding, consisting of unclipping and removal of the device, surgical reconstruction of the pulmonary artery is no longer required. ${ }^{24,25}$

FloWatch PAB obtains the same reduction of crosssectional area as does conventional circular banding and therefore the same pressure gradient, without any reduction of the perimeter of the pulmonary artery, as in conventional banding. By maintaining an intact circumference, with the possibility of growth, the wall of the pulmonary artery can maintain intact its anatomic properties, without any reduction in elasticity. The simple device removal at the time of intracardiac repair is enough to obtain spontaneous and complete expansion of the wall of the pulmonary artery, with maintenance of its elasticity and pliability. ${ }^{25}$

Despite the proved clinical advantages, the main criticism from colleagues, hospital administrators, and insurance companies relates to the price of the device $(\$ 10,000)$ when compared with a conventional band.

This prospective study, approved by the institutional ethical committee, has been designed to compare the results obtained with conventional pulmonary artery banding (conv-PAB) with those obtained with FloWatch PAB (FW$\mathrm{PAB}$ ) in 2 homogeneous groups of infants undergoing $\mathrm{PAB}$ in the same period and the costs related to each treatment strategy.

\section{Materials and Methods}

From 2003 through July 2006, 40 consecutive infants underwent either conv-PAB or FW-PAB. The characteristics of the patient population are presented in Table 1 .

There were 3 indications for PAB: 

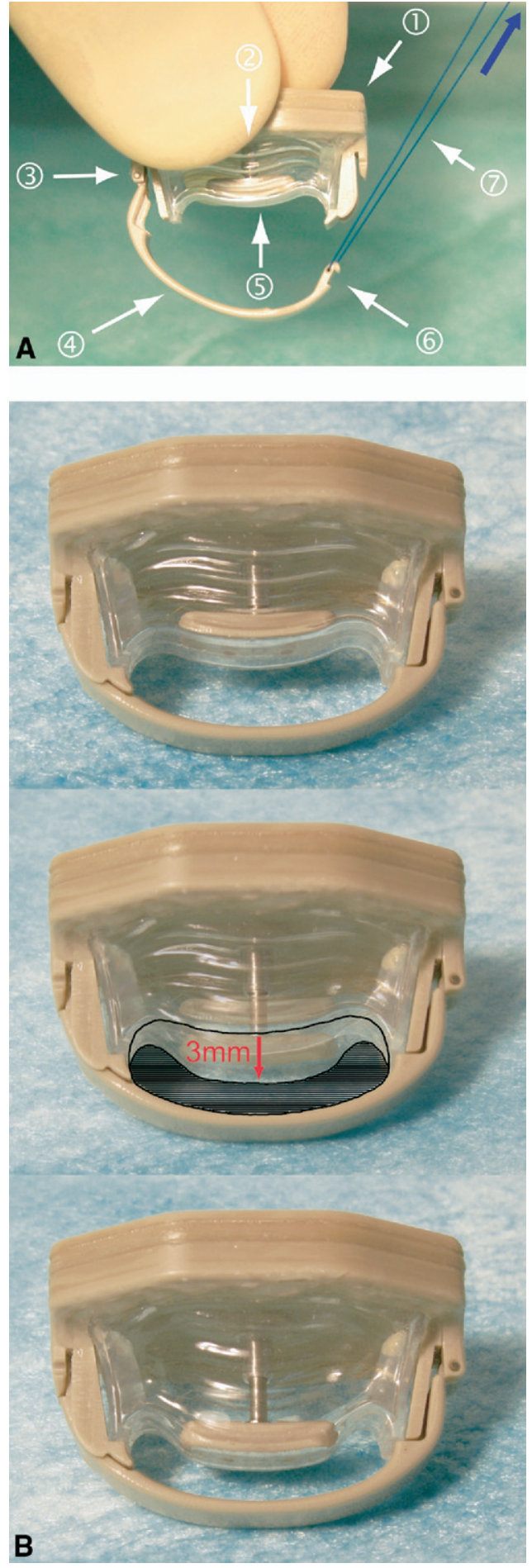

(1) preparation for a biventricular type of repair (16 [80\%] of 20 for conv-PAB and 13 [65\%] of 20 for FW-PAB) in infants with multiple ventricular septal defects, ventricular septal defect, or atrioventricular septal defect associated with hypoplasia or interruption of the aortic arch or by the clinical conditions of the infant (eg, prolonged mechanical
Figure 1. A, General view of the FloWatch device. 1, Box with all the necessary equipment to activate the adjustment mechanism: a small motor, an antenna able to receive the energy, and signals sent by the external antenna of the FloWatch Control Unit and electronics able to extract the energy and to interpret the signal and drive the motor. 2, Piston that narrows or releases the pulmonary artery. 5, Silicone membrane covering the piston. 4, Counterpiece designed to be closed around the pulmonary artery; one side is attached permanently to the box with a hinge (3), and the other side can be fixed onto the box with a clip (6). Near the clip is a hole to fix a suture loop (7) useful to pass the counterpiece behind the pulmonary artery and to clip the device. The sizes of the FloWatch when clipped are $26 \times 18.4 \times 17 \mathrm{~mm}$ (length $\times$ width $\times$ height). B, Top, View of the FloWatch implant in the completely open position. Middle, Superposed view of a completely open and a maximally closed FloWatch implant. The piston has a stroke of $\mathbf{3 m}$ for tightening or releasing the band. The silicone membrane is flexible and extensible, protecting the piston and the inside of the case from body fluids while allowing the piston to perform its adjustment movements. The adjustable surface where the pulmonary artery is confined varies with the displacement of the piston. The 3-mm piston stroke causes a variation of the adjustable surface between 72 and $38 \mathrm{~mm}^{2}$ with great precision. Bottom, View of the FloWatch implant in the maximally closed position.

ventilation with recurrent chest infections and episodes of respiratory insufficiency);

(2) preparation for a univentricular type of repair (2 [10\%] of 20 for conv-PAB and 5 [25\%] of 20 for FW-PAB) in functionally univentricular hearts with pulmonary hypertension; and

(3) left ventricular retraining (2 [10\%] of 20 for conv-PAB and 2 [10\%] of 20 for FW-PAB) in infants with transposition of the great arteries with late referral and in congenitally corrected transposition of the great arteries.

The only statistically significant difference $(P<.005)$ between the 2 groups was mean duration of preoperative mechanical ventilation, which was $3.3 \pm 4.3$ days (range, $0-15$ days) in the conv-PAB group and $17.5 \pm 19.0$ days (range, $0-60$ days) in the FW-PAB group (Table 1).

The assignment of infants to one or the other group has been dictated by the availability of the device. The availability was determined by the initial cost of the FW-PAB device $(\$ 10,000)$. Because of the budgetary constraints within our institution, the device was only intermittently available for clinical use. When there were more infant candidates for PAB than devices available, the FW-PAB device was, in general, reserved for the infants more likely to have difficult postoperative management, such as patients with prolonged preoperative mechanical ventilation, patients in preparation for a univentricular type of repair, or both. The final decision was always a joint agreement reached during our weekly departmental case discussion meeting. All patients were operated on by one of the 2 surgeons (AFC and MP) and managed during the entire perioperative period by the same team, according to the same clinical protocols. 
TABLE 1. Patient population

\begin{tabular}{lccc}
\hline & Conventional PAB & FloWatch PAB & $\begin{array}{r}\text { Statistical } \\
\text { difference }\end{array}$ \\
\hline Patient no. & 20 & 20 & NS \\
Mean age (range) & $1.8 \pm 1.5 \mathrm{mo}(6 \mathrm{~d}-5 \mathrm{mo})$ & $2.6 \pm 1.3 \mathrm{mo}(7 \mathrm{~d}-6 \mathrm{mo})$ & $\mathrm{NS}$ \\
Mean weight (range) & $3.7 \pm 0.7 \mathrm{~kg}(2.5-5.5 \mathrm{~kg})$ & $4.1 \pm 0.8 \mathrm{~kg}(2.7-5.7 \mathrm{~kg})$ & $\mathrm{NS}$ \\
Previous operation Indication & $5 / 20(25 \%)$ & $6 / 20(30 \%)$ & $\mathrm{NS}$ \\
$\quad$ Biventricular repair & $16 / 20(80 \%)$ & $13 / 20(65 \%)$ & $\mathrm{NS}$ \\
Univentricular repair & $2 / 20(10 \%)$ & $5 / 20(25 \%)$ & $\mathrm{NS}$ \\
$\quad$ LV retraining & $2 / 20(10 \%)$ & $2 / 20(10 \%)$ & $\mathrm{NS}$ \\
Preoperative mechanical ventilation: & $12 / 20(60 \%)$ & $14 / 20(70 \%)$ & NS \\
$\quad$ No. & $3.3 \pm 4.3 \mathrm{~d}(0-15 \mathrm{~d})$ & $17.5 \pm 19.0 \mathrm{~d}(0-60 \mathrm{~d})$ & $P<.005$ \\
Mean duration (range) & $11 / 20(55 \%)$ & $11 / 20(55 \%)$ & $\mathrm{NS}$ \\
Associated procedures & &
\end{tabular}

$P A B$, Pulmonary artery banding; $N S$, not significant; $L V$, left ventricular.

In both groups the $\mathrm{PAB}$ was performed through a median sternotomy. Conv-PAB was accomplished with a 4-mm Teflon band, premeasured with the Trusler rule, and adjusted intraoperatively according to the measured distal pulmonary artery pressure and systemic oxygen saturation. Implantation of the FW-PAB was performed by using the same surgical approach for the conv-PAB, with simple clipping of the device around the pulmonary artery and without intraoperative measurement of the distal pulmonary artery pressures but with telemetric adjustments of the device, guided by means of Doppler echocardiography, after transfer of the patient to the ICU.

The 2 groups have been compared by collecting the following data: (1) early and late deaths; (2) duration of postoperative mechanical ventilation and length of stay in the ICU and hospital; (3) need for any PAB-related reoperations to tighten, release, or both the conv-PAB versus need for telemetric adjustments of the FW$\mathrm{PAB}$ to either narrow the device, release the device, or both; and (4) costs of the mean stay in the ICU (\$3000 per patient per day) and in the hospital ( $\$ 1500$ per patient per day) and costs for reoperations ( $\$ 6500$ for 1 off-bypass operation).
The end points of this prospective study were as follows: (1) death; (2) debanding (or removal of the device) during the intracardiac repair; and (3) the end of January 2007 for all the remaining patients waiting for intracardiac repair.

The paired Student $t$ test was used for comparisons between the 2 groups.

\section{Results}

The clinical results are presented in Table 2 . There were 5 deaths, 3 early and 2 late, in the conv-PAB group. The early deaths (1, 15, and 20 days after the operation) occurred because of cardiac arrest during tracheal suctioning, inexorable heart failure, and multiorgan failure, whereas the late deaths ( 2 and 3 months after the operation) followed sepsis and heart failure. There were 2 deaths in the FW-PAB group, none early and 2 late ( 2 and 3 months after the operation); these deaths followed respiratory infection and neurologic damage.

TABLE 2. Results

\begin{tabular}{|c|c|c|c|}
\hline & Conventional PAB & FloWatch PAB & $\begin{array}{l}\text { Statistical } \\
\text { difference }\end{array}$ \\
\hline Mean follow-up (range) & $10.8 \pm 9.6 \mathrm{mo}(1-33 \mathrm{mo})$ & $13.4 \pm 10.4 \mathrm{mo}(1-38 \mathrm{mo})$ & NS \\
\hline \multicolumn{4}{|l|}{ Deaths } \\
\hline Early & 3 & 0 & NS \\
\hline Late & 2 & 2 & NS \\
\hline Total & $5 / 20(25 \%)$ & $2 / 20(10 \%)$ & NS \\
\hline \multicolumn{4}{|l|}{ Postoperative mechanical ventilation } \\
\hline Mean duration (range) & $10.4 \pm 11.2 \mathrm{~d}(1-51 \mathrm{~d})$ & $3.0 \pm 3.1 \mathrm{~d}(1-7 \mathrm{~d})$ & $P<.01$ \\
\hline \multicolumn{4}{|l|}{ Stay in ICU } \\
\hline Mean duration (range) & $20.3 \pm 19.9 d(1-51 d)$ & $5.3 \pm 4.6 \mathrm{~d}(1-20 \mathrm{~d})$ & $P<.005$ \\
\hline \multicolumn{4}{|l|}{ Stay in hospital } \\
\hline Mean duration (range) & $45.6 \pm 41.6 \mathrm{~d}(5-182 \mathrm{~d})$ & $15.4 \pm 6.4 d(6-30 d)$ & $P<.005$ \\
\hline Re-do PAB & $7 / 20(35 \%)$ & $0 / 20(0 \%)$ & $P<.005$ \\
\hline Pulmonary artery reconstruction at repair & $10 / 12(83 \%)$ & $0 / 7(0 \%)$ & $P<.0005$ \\
\hline
\end{tabular}

$P A B$, Pulmonary artery banding; NS, not significant; ICU, intensive care unit. 


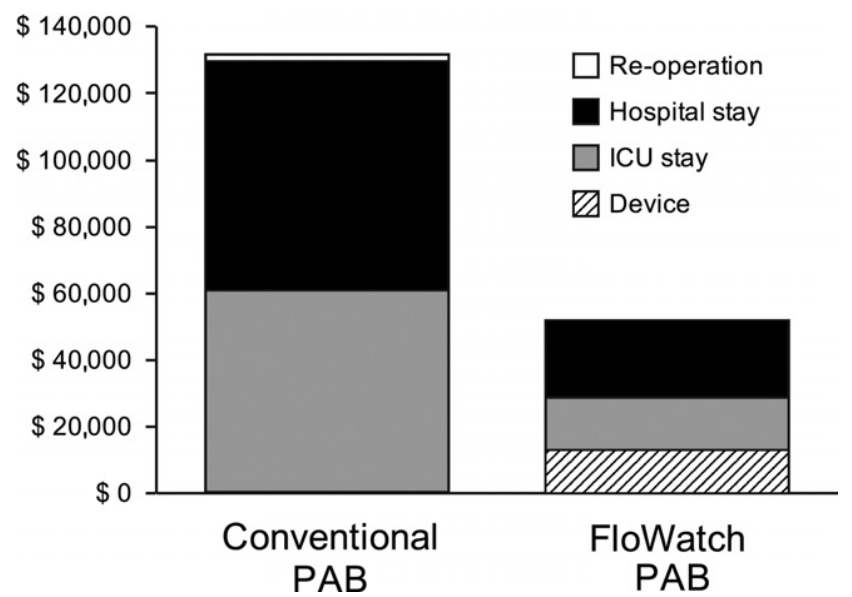

Figure 2. Cost comparison of the 2 techniques. ICU, Intensive care unit; $P A B$, pulmonary artery banding.

PAB-related reoperation was required in 7 (35\%) of 20 infants after conv-PAB to adjust the band. No reoperations were required after FW-PAB $(P<.005)$. There was a mean of $3.3 \pm 1.3$ (range, $1-5$ ) telemetric adjustments per infant to narrow the FW-PAB and $0.7 \pm 1.0$ (range, 0-3) to release it.

During the follow-up period, 19 patients underwent intracardiac repair and pulmonary artery debanding, 12 in the conv-PAB group and 7 in the FW-PAB group. None of these 19 patients died. Ten of the 12 patients with conv$\mathrm{PAB}$ required surgical enlargement of the main pulmonary artery, with a patch of heterologous pericardium to relieve residual stenosis after band removal. No reconstructive procedure of the pulmonary artery was required in all patients of the FW-PAB group because complete expansion of the pulmonary artery to its normal size followed removal of the device $(P<.0005)$.

At the end of the period of observation, 3 patients in the conv-PAB group and 12 patients in the FW-PAB group were waiting for intracardiac repair.

With regard to the cost calculation (Figure 2), only considering the average cost per patient of ICU $(\$ 60,900$ in the conv-PAB group and $\$ 15,900$ in the FW-PAB group) and hospital (\$68,400 in the conv-PAB group and $\$ 23,100$ in the FW-PAB group) stay and the average cost of reoperation $(\$ 2275)$ to adjust the conv-PAB, the average cost per patient was $\$ 92,575$ cheaper with FW-PAB than with conv-PAB, largely surpassing the cost of the device $(\$ 10,000)$.

\section{Discussion}

In the last decade, PAB as a palliative procedure has largely been abandoned as a surgical technique in favor of early repair, with exceptions being neonates with functionally univentricular hearts and pulmonary hypertension requiring preparation for cavopulmonary connections. ${ }^{2,5,6,8-10}$ More recently, the indications for $\mathrm{PAB}$ have been revisited or accepted as an alternative surgical option in the following: (1) complete atrioventricular septal defects, ${ }^{2,4-7}$ particularly in the presence of advanced pulmonary hypertension ${ }^{2,4,7,26}$; (2) transposition of the great arteries with late referral ${ }^{11}$ and congenitally corrected transposition of the great arteries ${ }^{12-14}$ in which left ventricular retraining is required; and (3) hypoplastic left heart malformations as a rescue procedure in critically ill neonates or as an elective procedure in preparation for subsequent operations, either the Norwood procedure or heart transplantation. ${ }^{15-18}$ The continued interest in an adjustable PAB has been confirmed also in recent experimental $^{27-29}$ and clinical ${ }^{30}$ studies of new techniques.

The telemetrically adjustable PAB, which is now available with the FW-PAB device, an implantable, wireless, and battery-free device, gives the clinician the ability to repeatedly progressively narrow and reopen the pulmonary artery to a desired percentage of occlusion. Positive results have now been obtained in a number of different institutions. ${ }^{20-22}$

This device provides an adjustable PAB by means of remote control, avoiding any $\mathrm{PAB}$-related reoperation or other invasive procedure to adjust the band either way, tightening or releasing. ${ }^{19-22}$ The availability of this surgical armamentarium allows an easier management of complex infants ${ }^{20-22}$ and also avoids the pulmonary artery reconstruction when intracardiac repair is undertaken. ${ }^{24,25}$

The main criticism of FW-PAB from colleagues, hospital administrators, and insurance companies has always been its price $(\$ 10,000)$ when compared with that of the conventional band.

Our study of 2 homogeneous groups of patients undergoing conv-PAB or FW-PAB in the same period of time not only confirms the clinical advantages of FW-PAB over conv-PAB with a significantly shorter and less complicated postoperative course but also demonstrates the substantial reduction of costs with the FW-PAB, greatly outweighing the initial cost of the device.

\section{Limits of the Study}

The patients were not randomly selected for either group. Nevertheless, the only difference between the 2 groups was more difficult management for infants in the FW-PAB group because of a larger number of patients in preparation for a univentricular type of repair and because the duration of preoperative mechanical ventilation was significantly longer than in the conv-PAB group.

None of the clinicians involved in caring for the patients in the perioperative period were blinded with respect to the type of PAB used. In our opinion, it was important to provide this information in case of urgent need for PAB 
adjustment, either with chest reopening for conv-PAB or with the remote control for FW-PAB.

With regard to the cost calculation, only the costs of ICU and hospital stay and reoperations have been taken into account. The inclusion of additional costs, such as costs for the treatment of complications because of a longer stay in the ICU and hospital and costs for the pulmonary artery repair, at the time of the intracardiac repair would have further increased the difference between the conv-PAB and FW-PAB groups in favor of FW-PAB.

\section{Conclusions}

The flexibility provided by telemetrically controlled FWPAB is superior to that of conv-PAB because (1) it eliminates the need for reoperation to adjust the pulmonary artery band; (2) postoperative management is simplified and postoperative mechanical ventilation and length of stay in the ICU and hospital are significantly reduced, even in more compromised and difficult-to-manage infants; (3) the cost of the device is more than offset by the reduction in duration of postoperative mechanical ventilation, length of stay in the ICU and hospital, and avoidance of any PAB-related reoperation; and (4) pulmonary artery reconstruction is no longer required when intracardiac repair is undertaken.

We thank Gianluca Lucchese for his help in the initial data collection and all the colleagues and nurses involved with the perioperative care of the patients. Pierre Fridez, EndoArt, kindly provided the illustrations of the device.

\section{References}

1. Corno AF. Congenital heart defects. Decision making for surgery. Volume 1: Common defects, 2003, and Volume 2: Less common defects, 2004. Darmstadt (Germany): Steinkopff Verlag; 2004.

2. Takayama H, Sekiguchi A, Chikada M, Noma M, Ishizawa A, Takamoto S. Mortality of pulmonary artery banding in the current era: recent mortality of pulmonary artery banding. Ann Thorac Surg. 2002; 74:1219-23.

3. Brown JW, Ruzmetov M, Okada Y, Vijay P, Rodefeld MD, Turrentine MW. Outcomes in patients with interrupted aortic arch and associated anomalies: a 20-year experience. Eur J Cardiothorac Surg. 2006;29: 666-73.

4. Al Qethamy HO, Aboelnazar S, Aizaz K, Al Faraidi Y. Play safe: band the late presenting complete atrioventricular canal. Asian Cardiovasc Thorac Ann. 2002;10:31-4.

5. Yoshimura N, Yamaguchi M, Oka S, Yoshida M, Murakami $\mathrm{H}$. Pulmonary artery banding still has an important role in the treatment of congenital heart disease. Ann Thorac Surg. 2005;79:1463-4.

6. Piluiko VV, Poynter JA, Nemeh H, Thomas RL, Forbes TJ, Delius RE, et al. Efficacy of intraluminal pulmonary artery banding. $J$ Thorac Cardiovasc Surg. 2005;129:544-50.

7. Ohashi N, Matsushima M, Maeda M, Yamaki S. Two-stage procedure for pulmonary vascular obstructive disease in Down syndrome with congenital heart disease. Circ J. 2006;70:1446-50.

8. Lan YT, Chang RK, Laks H. Outcome of patients with double-inlet left ventricle or tricuspid atresia with transposed great arteries. $J \mathrm{Am}$ Coll Cardiol. 2004;43:113-9.

9. Karamlou T, Ashburn DA, Caldarone CA, Blackstone EH, Jonas RA, Jacobs ML, et al. Matching procedure to morphology improves outcomes in neonates with tricuspid atresia. J Thorac Cardiovasc Surg. 2005;130:1503-10.
10. Rodefeld MD, Ruzmetov M, Schamberger MS, Girod DA, Turrentine MW, Brown JW. Staged surgical repair of functional single ventricle in infants with unobstructed pulmonary blood flow. Eur J Cardiothorac Surg. 2005;27:949-55.

11. Corno AF, Hurni M, Payot M, Sekarski N, Tozzi P, von Segesser LK. Adequate left ventricular preparation allows for arterial switch despite late referral. Cardiol Young. 2003;13:49-52.

12. Devaney EJ, Charpie JR, Ohye RG, Bove EL. Combined arterial switch and Senning operation for congenitally corrected transposition of the great arteries: patient selection and intermediate results. J Thorac Cardiovasc Surg. 2003;125:500-7.

13. Winlaw DS, McGuirk SP, Balmer C, Langley SM, Griselli M, Stumper O, et al. Intention-to-treat analysis of pulmonary artery banding in conditions with a morphological right ventricle in the systemic circulation with a view to anatomic biventricular repair. Circulation. 2005;111:405-11.

14. Uno Y, Morita K, Ko Y, Kinouchi K. Double switch operation for congenitally corrected transposition of the great arteries after twostaged pulmonary artery banding. Jpn J Thorac Cardiovasc Surg. 2006;54:40-3

15. Ishizaka T, Ohye RG, Suzuki T, Devaney EJ, Bove EL. Bilateral pulmonary artery banding for resuscitation in hypoplastic left heart syndrome. Ann Thorac Surg. 2003;75:277-9.

16. Mitchell MB, Campbell DN, Boucek MM, Sondheimer HM, Chan $\mathrm{KC}$, Ivy DD, et al. Mechanical limitation of pulmonary blood flow facilitates heart transplantation in older infants with hypoplastic left heart syndrome. Eur J Cardiothorac Surg. 2003;23:735-42.

17. Pizarro C, Murdison KA. Off pump palliation for hypoplastic left heart syndrome: surgical approach. Semin Thorac Cardiovasc Surg Pediatr Card Surg Ann. 2005;8:66-71.

18. Takabayashi S, Shimpo H, Ozu Y, Yokoyama K, Kaijmoto M. A Fontan completion through stage I bilateral pulmonary artery banding for hypoplastic left heart syndrome. J Thorac Cardiovasc Surg. 2005; 130:1464-5.

19. Corno AF, Sekarski N, Bernath MA, Payot M, Tozzi P, von Segesser LK. Pulmonary artery banding: long-term telemetric adjustment. Eur J Cardiothorac Surg. 2003;23:317-22.

20. Corno AF, Bonnet D, Sekarski N, Sidi D, Vouhé P, von Segesser LK. Remote control of pulmonary blood flow: initial clinical experience. J Thorac Cardiovasc Surg. 2003;126:1775-80.

21. Sekarski N, Fridez P, Corno AF, von Segesser LK, Meijboom E Doppler guided regulation of a telemetrically operated adjustable pulmonary banding system. $J$ Am Coll Cardiol. 2004;44;1087-94.

22. Bonnet D, Corno AF, Sidi D, Sekarski N, Beghetti M, Schulze-Neick I, et al. Early clinical results of telemetric adjustable pulmonary artery banding FloWatchR-PAB. Circulation. 2004;110(suppl):II158-63.

23. Wernovsky G, Giglia TM, Jonas RA, Mone SM, Colan SD, Wessel DL. Course in the intensive care unit after "preparatory" pulmonary artery banding and aortopulmonary shunt placement for transposition of the great arteries with low left ventricular pressure. Circulation. 1992;86(suppl):II133-9.

24. Corno AF, Pozzi M, von Segesser LK. FloWatch and pseudoaneurysm: complication versus coincidence. J Thorac Cardiovasc Surg. 2006;131:928-9.

25. Corno AF, Prosi M, Fridez P, Zunino P, Quarteroni A, von Segesser LK. The non-circular shape of FloWatch-PAB prevents the need for pulmonary artery reconstruction after banding. Computational fluid dynamics and clinical correlations. Eur J Cardiothorac Surg. 2006; 29:93-9.

26. Ohashi N, Matsushima M, Maeda M, Yamaki S. Two-stage procedure for pulmonary vascular obstructive disease in Down syndrome with congenital heart disease. Circ J. 2006;70:1446-50.

27. Santos Martinez LE, Gotes J, Flores P, Tena C, Graullera V, Pulido T, et al. Modification of a hydraulic device for controlled banding of the trunk of the pulmonary artery in dogs. Arch Cardiol Mex. 2005 75(suppl):S3-10-20

28. Boudjemline Y, Pineau E, Bonnet C, Mollet A, Abadir S, Bonnet D, et al. Off-label use of an adjustable gastric banding system for pulmonary artery banding. J Thorac Cardiovasc Surg. 2006;131 1130-5. 
29. Faber MJ, Dalinghaus M, Lankhuizen IM, Steendijk P, Hop WC, Schoemaker RG, et al. Right and left ventricular function after chronic pulmonary artery banding in rats assessed with biventricular pressurevolume loops. Am J Physiol Heart Circ Physiol. 2006;291:H1580-6.

30. Choudhary SK, Talwar S, Airan B, Mohapatra R, Juneja R, Kothari SS, et al. A new technique of percutaneously adjustable pulmonary artery banding. J Thorac Cardiovasc Surg. 2006;131:621-4.

\section{Discussion}

Mr Cliff K. Choong (Cambridge, United Kingdom). Congratulations on your very good study and results. Based on this, have you changed your practice to use this device for all your subsequent patients?

Dr Corno. First of all, we now can use this device in any patient because the hospital administration is convinced that, despite the initial cost, we can spare the money.

Regarding the management, we changed a lot of policies. For instance, patients with multiple ventricular septal defects are now, in the neonatal period, treated with this device. Now we have a group of 5 patients, on average 2 to 3 years after surgical intervention, and we follow all of them. Of course, when the patient grows and the body weight increases, we can release the device to avoid the right ventricular pressure becoming suprasystemic. And in 4 patients all multiple ventricular septal defects, $2 \frac{1}{2}$ to 3 years after surgical intervention, underwent spontaneous closure. Two weeks ago, I operated on one patient, removing the device, and without anything else required, even the pulmonary artery reconstruction was not necessary. Much easier is the management, of course, of a univentricular heart, for obvious reasons, because you can titrate the distal pulmonary artery pressure as you want based on echocardiographic results. In the group for left ventricular retraining, we have only 4 patients, but the number is increasing and, of course, in the future, with this device available for left ventricular retraining.

Mr Choong. Second, do you recommend that all pediatric surgeons should now be using this rather than conv-PAB?

Dr Corno. Yes. It changes from the night to the day.

Mr Choong. Lastly, the device seems to be flawless. Are there any short- or long-term complications associated with this device?

Dr Corno. We have found complications with this device caused by the fact that the piston is covered by a silicone membrane to prevent damage to the pulmonary artery. We had one complication in one of the animals in the clinical study and in 2 patients, one in another center and one in our center, because if you go close to the membrane with any sharp instrument, like a needle or knife, you can produce a hole in the membrane, the pericardial fluid enters into the device, and then the micromotor stops working. Then you remain with a conventional banding.

Dr Renato Assad (Sao Paulo, Brazil). First of all, I would like to congratulate Dr Corno and his colleagues for the very ingenious FloWatch and his work on adjustable PAB.

I would like to share with the association the first case in which a high-risk neonate with hypoplastic left heart syndrome was initially managed with a miniadjustable PAB system in both pulmonary arteries. The banding system is entirely silicone covered, a miniaturized and improved device developed from our previous experimental studies that resulted in a more delicate banding system for neonatal use with a 4-mm diameter. Ten percutaneous adjustments of the banding system were necessary to keep the arterial oxygen saturation in the 75 to 85 range before the second stage. The Norwood operation and bidirectional Glenn shunt were carried out on the 106th day of life, and the total cavopulmonary connection was carried out in the 21 st month of life. There was no pulmonary artery distortion after removing the bands.

The clinical use of this innovative PAB system allowed for a customization of the pulmonary blood flow according to the underlying clinical needs, resulting in a more precise balance between the pulmonary and systemic circulations.

I have a question for Dr Corno regarding the left ventricular retraining patient. How was the length of time comparing the 2 systems?

I thank the association for the opportunity to make these comments about your new prototype.

Dr Corno. Thank you, Dr Assad, for the question. Of course I am familiar with your article, and I can tell you at the moment that there is no indication of using this device when you need a bilateral banding. The first reason is the size of the device, and the second is the cost. You will need to do another study and have discussions with the hospital administrators.

To answer your question, the interval depends on the adaptability of the new system. We follow this with echocardiography, and we want, of course, to obtain almost systemic pressure in the new systemic ventricle. From a study done when I was in Lausanne, ${ }^{11}$ we calculated with the echocardiographic analysis the ratio between the thickness of the free wall of the right ventricle versus the left ventricle. When you have reached the inversion of the ratio, it means that we have reached a high enough level of left ventricular hypertrophy or hyperplasia according to the age of the child, and then we can go for the arterial switch operation.

Dr Pedro Becker (Santiago, Chile). That was very interesting, Antonio, but what bothers me is that I do not find here the key end point that you are pursuing when you band the pulmonary artery. To me, mortality is such a gross end point. Pulmonary artery bands are designed to either decrease pulmonary artery pressure, limit $\mathrm{Qp} / \mathrm{Qs}$, or retrain the left ventricle. Therefore I think it would be very interesting to really know whether the goals of the PAB were properly accomplished with this device in a better way than the conventional technique and therefore convince us surgeons not to use just the regular PAB any more. Congratulations, anyway.

Dr Corno. Thank you. First of all, you can discuss the indication for banding versus repair. These patients, in our experience, were without indication for a repair because either they were in for a univentricular type of repair (and you cannot perform a cavopulmonary connection in the first weeks of life) or in for left ventricular retraining. In case of biventricular repair, we had patients with unbalanced complete atrioventricular septal defect, multiple ventricular septal defects, ventricular septal defect with aortic coarctation, and hypoplasia of the aortic arch. Most patients were referred after 1 or 2 months in the ICU on mechanical ventilation. In our experience these patients did not constitute a good indication for banding. Then you have to decide between a conventional banding and an adjustable banding. The main difference is the management in the immediate postoperative course. 
With a fixed band, either you have to go back and reopen the chest 2 or 3 times, particularly when you need for univentricular heart or left ventricular retraining, whereas with this device you can simply go in the operating room, perform a much faster procedure, and clip the band and close the chest, and you do all the adjustments after the operation. You can do it progressively within days or weeks, and this is much better tolerated than the conventional banding, when you have to suddenly change the hemodynamics.

\section{ON THE MOVE?}

Don't miss a single issue of the journal! To ensure prompt service when you change your address, please photocopy and complete the form below.

Please send your change of address notification at least six weeks before your move to ensure continued service. We regret we cannot guarantee replacement of issues missed due to late notification.

\section{JOURNAL TITLE:}

Fill in the title of the journal here.

\section{OLD ADDRESS:}

Affix the address label from a recent issue of the journal here.

\section{NEW ADDRESS:}

Clearly print your new address here.

Name

Address

City/State/ZIP
COPY AND MAIL THIS FORM TO:

Elsevier Inc.

Subscription Customer Service

6277 Sea Harbor Dr

Orlando, FL 32887
OR FAX TO:

407-363-9661

OR E-mail:

elspcs@elsevier.com
OR PHONE:

800-654-2452

Outside the U.S., call

407-345-4000 